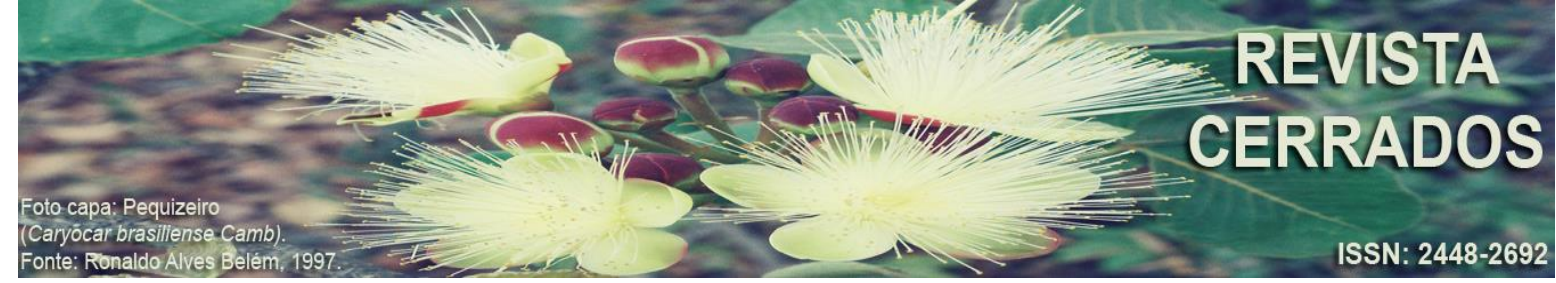

\title{
ESTADO DE CONSERVAÇÃO DAS ÁREAS DE PRESERVAÇÃO PERMANENTES DE NASCENTES DA BACIA HIDROGRÁFICA DO RIO JAURU/MT-BRASIL
}

\section{CONSERVATION STATUS OF THE AREAS OF PERMANENT PRESERVATION OF SPRINGS OF THE JAURU RIVER BASIN/MT- BRAZIL}

\section{ESTADO DE CONSERVACIÓN DE LAS ZONAS DE PRESERVACIÓN PERMANENTES DE LOS MANANTIALES DE LA CUENCA DEL RÍO JAURU/MT-BRASIL}

\author{
Gessica de Jesus Oliveira Silva \\ Universidade do Estado de Mato Grosso - UNEMAT, Cuiabá, Mato Grosso, Brasil \\ E-mail: <gessica.unemat@gmail.com> \\ Sandra Mara Alves da Silva Neves \\ Universidade do Estado de Mato Grosso - UNEMAT, Cuiabá, Mato Grosso, Brasil \\ E-mail: 〈ssneves@unemat.br> \\ Alexander Webber Perlandim Ramos \\ Universidade Federal de Minas Gerais - UFMG, Belo Horizonte, Minas Gerais, Brasil \\ E-mail: <webber.unemat@gmail.com> \\ Miriam Raquel da Silva Miranda \\ Universidade do Estado de Mato Grosso - UNEMAT, Cuiabá, Mato Grosso, Brasil \\ E-mail: <miriamraquel18@gmail.com>
}

\section{RESUMO}

O objetivo deste estudo é avaliar o estado de conservação das Áreas de Preservação Permanentes (APPs) de nascentes da bacia hidrográfica do rio Jauru (BHRJ), no Estado brasileiro de Mato Grosso. Para tanto, foram utilizadas ferramentas geotecnologicas para identificação das nascentes e delimitação de suas APPs, conforme os dispostos da Lei 12.651/2012. A mensuração do estado ambiental de conservação da paisagem foi realizada por meio da aplicação do Índice de Transformação Antrópica (ITA). No período de três décadas (1986-2016), foi identificado na BHRJ um constante processo de supressão vegetal, tendo um decréscimo de $90 \%$, em decorrência do desmate para o desenvolvimento da 
SILVA, G. J. O.; NEVES, S. M. A. S.; RAMOS, A. W. P.; MIRANDA, M. R. S.

Estado de conservação das áreas de preservação permanente de nascentes da bacia hidrográfica do rio Jauru/MTBrasil

implantação da pecuária, principal atividade econômica dos municípios que compõem a bacia. O ITA evidenciou que sete das nove sub-unidades hidrográficas estão em estado degradado. A bacia do rio Jauru apresentou desmatamento crescente durante o período analisado, incluindo suas APPs. Diante disso, a necessidade de planejamento do uso da terra na bacia é de extrema importância ambiental, visto sua contribuição hídrica ao bioma Pantanal.

Palavras-chave: Geotecnologias. Pantanal. Conservação ambiental.

\begin{abstract}
The aim of this study is to evaluate the conservation status of permanent preservation areas (APPs) of springs of the Jauru River river basin (BHRJ), in the Brazilian State of Mato Grosso. For this, geotechnological tools were used to identify the springs and delimit their APPs, according to those in law 12.651/2012. The measurement of the environmental state of conservation of the landscape was performed through the application of the Anthropic Transformation Index (ITA). In the period of three decades (1986-2016), a constant process of plant suppression was identified in BHRJ, with a decrease of $90 \%$, due to the decrease in the development of livestock activity, the main economic activity of the municipalities that make up the basin. The ITA showed that seven of the nine hydrographic subunits are in a degraded state. The Jauru River basin showed increasing deforestation during the analyzed period, including its APPs. Therefore, the need to plan land use in the basin is extremely environmentally important, given its water contribution to the Pantanal biome.
\end{abstract}

Keywords: Geotechnologies. Pantanal. Environmental conservation.

\title{
RESUMEN
}

El objetivo de este estudio es evaluar el estado de conservación de las áreas de conservación permanente (APP) de los manantiales de la cuenca del río Jauru (BHRJ), en el estado brasileño de Mato Grosso. Para ello, se utilizaron herramientas geotecnológicas para identificar los manantiales y delimitar sus APPs, de acuerdo con las de la ley 12.651/2012. La medición del estado ambiental de conservación del paisaje se realizó mediante la aplicación del índice de transformación antrópico (ITA). En el período de tres décadas (1986-2016), se identificó un proceso constante de supresión de plantas en BHRJ, con una disminución del $90 \%$, debido a la disminución en el desarrollo de la actividad ganadera, la principal actividad económica de los municipios que componen la cuenca. El ITA mostró que siete de las nueve subunidades hidrográficas se encuentran en un estado degradado. La cuenca del río Jauru mostró una creciente deforestación durante el período analizado, incluyendo sus APPs. Por lo tanto, la necesidad de planificar el uso de la tierra en la cuenca es extremadamente importante para el medio ambiente, dada su contribución al agua al bioma del Pantanal.

Palabras-clave: Geotecnologías. Pantanal. Conservación ambiental. 
SILVA, G. J. O.; NEVES, S. M. A. S.; RAMOS, A. W. P.; MIRANDA, M. R. S.

Estado de conservação das áreas de preservação permanente de nascentes da bacia hidrográfica do rio Jauru/MTBrasil

\title{
INTRODUÇÃO
}

As constantes modificações ambientais ocasionadas pelas ações antrópicas têm gerado diversos problemas ambientais, afetando o estado de equilíbrio ecológico das paisagens. De acordo com Ross (2006) apud Ramos et al. (2018), a dinâmica dos ambientes naturais mostra-se em equilíbrio dinâmico, até que as sociedades, progressivamente, passam a intervir intensamente na exploração dos recursos naturais.

Dentre os principais componentes ambientais que sofrem com as ações humanas estão os sistemas hídricos, que incluem cabeceiras de drenagem e zonas de nascentes. As nascentes são exteriorizações dos lençóis freáticos que dão origem aos corpos d'água, que dependem quanto à sua perenidade da proteção de suas Áreas de Preservação Permanentes (VALENTE; GOMES, 2005; LORENZON et al., 2015).

\begin{abstract}
A cobertura florestal em áreas definidas como Áreas de Preservação Permanente constitui-se em elemento de extrema importância na manutenção da qualidade ambiental, desempenhando diversas funções, entre as quais, a dissipação da energia do escoamento superficial, a proteção das margens dos cursos d'água, a estabilização de encostas, a proteção de nascentes, o impedimento do assoreamento de corpos d'água, o abastecimento do lençol freático e a captura e retenção de carbono, sendo que tais funções muitas vezes ficam comprometidas, decorrente de sua falta (NARDINI et al., 2019, p. 645).
\end{abstract}

Sendo assim, a execução de diagnósticos ambientais que busquem quantificar os principais impactos sobre o meio ambiente, em especial nas Áreas de Preservação Permanentes, e norteiem medidas para mitigação das pressões geradas sobre os sistemas ambientais, se fazem de extrema importância para a proteção e garantia de estabilidade ecológica das paisagens (DESTRO; CAMPOS, 2007).

Nesse contexto, o monitoramento das alterações da cobertura vegetal e do uso da terra, por meio das geotecnologias, constituem-se uma alternativa viável para se reduzir significativamente o tempo e os custo no processo de acompanhamento ambiental (ALVES; FERREIRA, 2016; MACEDO et al., 2017). Miranda et al. (2019) destacam que a automatização da produção de documentos cartográficos viabilizados por tais ferramentas, favorece o processo de gestão ambiental e territorial, por conta da elevada eficiência, precisão e qualidade das informações geradas. Diante da contextualização apresentada, o objetivo deste estudo é avaliar o estado de conservação das Áreas de Preservação Permanente de nascentes 
SILVA, G. J. O.; NEVES, S. M. A. S.; RAMOS, A. W. P.; MIRANDA, M. R. S.

Estado de conservação das áreas de preservação permanente de nascentes da bacia hidrográfica do rio Jauru/MTBrasil

da bacia hidrográfica do rio Jauru, no Estado brasileiro de Mato Grosso, em virtude da importância de suas águas para a sociedade e o equilíbrio do bioma Pantanal, a qual a bacia é contribuinte hídrica.

\section{MATERIAIS E MÉTODOS}

\section{Área de estudo}

A bacia hidrográfica do rio Jauru (BHRJ), situada no Estado de Mato Grosso, possui uma extensão territorial de $11.697,72 \mathrm{~km}^{2}$, distribuída em quatorze municípios (Figura 1). A BHRJ é composta por nove sub-bacias, sendo elas: Bacia hidrográfica córrego Água Suja (2,34\%), Bacia hidrográfica córrego Sangue (2,70\%), Bacia hidrográfica córrego Padre Ribeirão (1,80\%), Bacia hidrográfica córrego Santíssimo (10,38\%), Bacia hidrográfica rio Aguapeí (16,13\%), Bacia hidrográfica córrego Brigadeiro (6,26\%), Bacia hidrográfica Ribeirão Caeté (7,18\%), Bacia hidrográfica Ribeirão Pitas (10,84\%) e Interbacia do rio Jauru $(42,36 \%)$ (LUZ, 2018).

Figura 1 - Bacia hidrográfica do rio Jauru nos contextos hidrográfico e intermunicipal

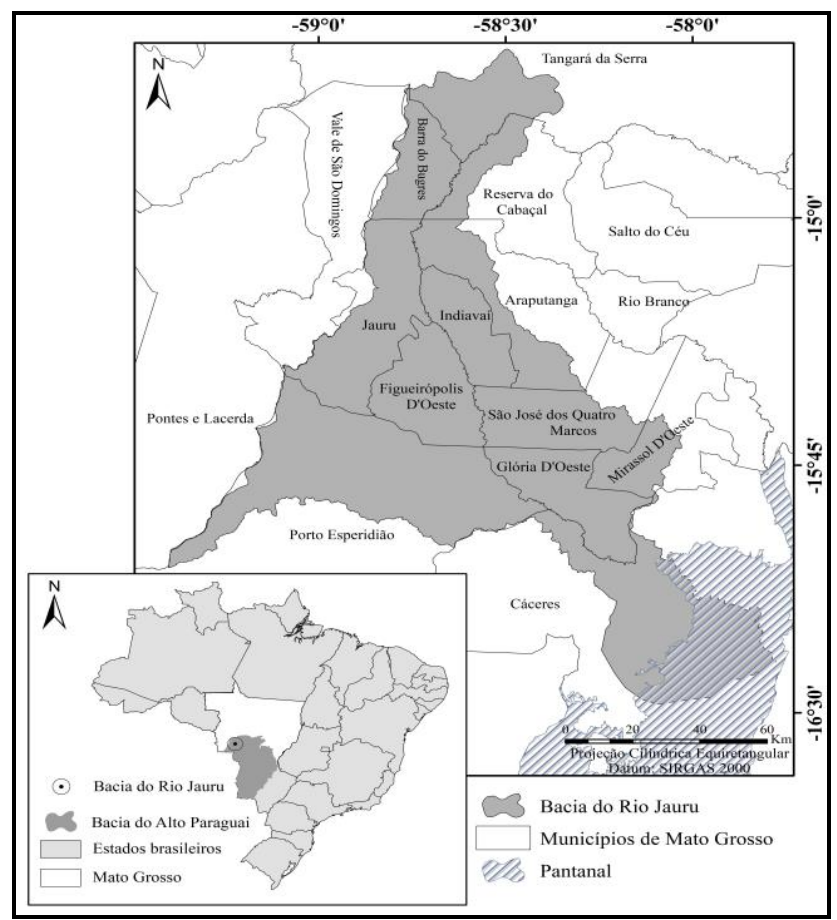

Fonte: os autores (2017).

Revista Cerrados, Montes Claros/MG, v.18, n. 1, p. 03-22, jan./jun.-2020 
SILVA, G. J. O.; NEVES, S. M. A. S.; RAMOS, A. W. P.; MIRANDA, M. R. S.

Estado de conservação das áreas de preservação permanente de nascentes da bacia hidrográfica do rio Jauru/MTBrasil

\section{Procedimentos metodológicos}

Para a geração dos mapas de cobertura vegetal e usos da terra, foram obtidas no sítio do Instituto Nacional de Pesquisas Espaciais (INPE) imagens do satélite Landsat 5, sensor Thematic Mapper (TM), dos anos de 1986, 1996 e 2006, e imagens do satélite Landsat 8, sensor Operational Land Imager (OLI), ambas com resolução espacial de 30 metros. Para as imagens do satélite Landsat 5, foi realizado o processo de georreferenciamento, que consiste na correção das distorções geométricas, minimizando e/ou eliminando o erro de posicionamento (OLIVEIRA et al., 2018).

No Sistema de Processamento de Informações Georreferenciadas (SPRING), versão 5.3, do INPE (CÂMARA et al., 1996), foi criado um Banco de Dados Geográfico (BDG) com as seguintes informações cartográficas: Projeção - Universal Transversa de Mercator; Datum - SIRGAS 2000; e Retângulo Envolvente - Long 1 (6000’00”) e Long 2

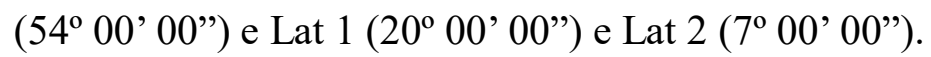

No BDG, foi realizada a importação das imagens para execução do mosaico e recorte utilizando como máscara a área de estudo. Em seguida, realizou-se a segmentação, por meio do método de crescimento de regiões para agrupar os "pixels" adjacentes e semelhantes, gerando regiões homogêneas, fazendo uso dos limiares de similaridade 10 e área de pixel 15 para as imagens do Landsat 5 e similaridade 50 e área de pixel 80 para as do Landsat 8 . A dissimilitude desses valores decorre da diferença de resolução radiométrica entre os satélites Landsat 5 e Landsat 8, que é de 8 e 16 bits, respectivamente.

$\mathrm{Na}$ classificação, foi usado o classificador supervisionado por regiões Bhattacharya que utiliza a distância para aferir a separabilidade entre cada par de classes espectrais. Na sequência, foram definidas as classes temáticas do mapeamento, utilizando o sistema classificação do Manual Técnico de Vegetação e Uso da Terra (IBGE, 2013) e os relatórios do Projeto de Conservação e Utilização Sustentável da Diversidade Biológica Brasileira - PROBIO Pantanal, Cerrado e Amazônia (BRASIL, 1999). O arquivo vetorial da classificação foi exportado no formato shapefile (.shp) para edição e quantificação no programa ArcGis, versão 10.5 (ESRI, 2017). Os erros de rotulação de classes foram corrigidos por meio da edição de polígonos, caso existisse discordância entre os resultados da classificação e a realidade verificada por meio de trabalho de campo. 
SILVA, G. J. O.; NEVES, S. M. A. S.; RAMOS, A. W. P.; MIRANDA, M. R. S.

Estado de conservação das áreas de preservação permanente de nascentes da bacia hidrográfica do rio Jauru/MTBrasil

Para a execução do mapeamento das nascentes, foi utilizado o método de interpretação visual por meio das imagens geradas pelo satélite RapidEye, com resolução espacial de 5 metros, disponibilizadas pelo Ministério do Meio Ambiente. Nos pontos das nascentes, aplicou-se a ferramenta Buffer, definindo como raio a distância de 50 metros, conforme previsto na Lei Complementar 12.651/2012 (BRASIL, 2012), que dispõe sobre os parâmetros de delimitação das Áreas de Preservação Permanente de nascentes.

Após ter sido gerado o limite das Áreas de Preservação Permanente (APPs) das nascentes, ele foi utilizado como máscara para o recorte do mapa de cobertura vegetal e usos da terra, sendo possível quantificar e analisar as classes presentes nas APPs das nascentes. Por fim, elaborou-se os encartes do mapa e as quantificações.

Para a mensuração do estado de conservação da paisagem na bacia, foi aplicado o Índice de Transformação Antrópica (ITA) desenvolvido por Lémechev e aplicado em estudos no Mato Grosso por Gouveia et al. (2013), Rodrigues et al. (2015) e Miranda et al. (2019), expresso na fórmula 1:

$$
I T A: \sum(\% U S O * P E S O) / 100
$$

Sendo: USO = área em valores percentuais da classe de cobertura vegetal e uso da terra; e PESO = valores indicados aos diferentes tipos de cobertura vegetal e uso da terra quanto ao grau de alterações antrópicas. A categoria peso varia de 1 a 10, sendo quanto maior a proximidade do peso 10 maiores são as pressões (Tabela 1). Os resultados do ITA foram classificados de acordo com Cruz et al. (1998) em: pouco degradados (0 - 2,5), regular (2,5 5), degradado (5 - 7,5) e muito degradado (7,5 - 10).

Tabela 1 - Pesos atribuídos as classes cobertura vegetal e usos da terra da BHRJ

\begin{tabular}{lc}
\hline Classes & Pesos \\
\hline Agricultura & 8,00 \\
Água & 2,00 \\
Pecuária com presença de savana & 5,00 \\
Pecuária com presença de vegetação secundária & 6,00 \\
Ecótono & 1,00 \\
Floresta & 1,00 \\
Áreas degradadas por mineração & 10,00 \\
Influência Urbana & 9,70 \\
Savana & 1,00 \\
Silvicultura & 1,00 \\
\hline
\end{tabular}

Fonte: os autores (2017). 
SILVA, G. J. O.; NEVES, S. M. A. S.; RAMOS, A. W. P.; MIRANDA, M. R. S.

Estado de conservação das áreas de preservação permanente de nascentes da bacia hidrográfica do rio Jauru/MTBrasil

\section{RESULTADOS E DISCUSSÕES}

Ao longo do período analisado, de três décadas, a bacia hidrográfica do rio Jauru passou por diversas alterações decorrentes da ação antrópica. A soma das atividades humanas na bacia apresentou um crescimento contínuo, de 42,23\% de sua área total no ano de 1986 para 54,15\%,63,11\% e 63,59\% nos anos de 1996, 2006 e 2016, respectivamente, sendo a Pecuária com presença de vegetação secundária principal atividade modificadora da paisagem (Tabela 2 e Figura 2).

Tabela 2 - Dinâmica da cobertura vegetal e usos da terra na BHRJ, nos anos de 1986, 1996, 2006 e 2016

\begin{tabular}{|c|c|c|c|c|c|c|c|}
\hline \multirow[b]{2}{*}{ Classe } & \multicolumn{2}{|c|}{1986} & \multicolumn{2}{|c|}{1996} & \multicolumn{2}{|c|}{2006} & \multirow{2}{*}{$\frac{2016}{\text { ha }}$} \\
\hline & ha & $\begin{array}{c}\text { Dinâmica } \\
(\%)\end{array}$ & ha & $\begin{array}{c}\text { Dinâmica } \\
(\%)\end{array}$ & ha & $\begin{array}{c}\text { Dinâmica } \\
(\%)\end{array}$ & \\
\hline Agricultura & $6.238,54$ & 76,75 & $15.838,07$ & 40,97 & $12.556,38$ & 53,20 & $26.830,40$ \\
\hline Água & $19.458,13$ & $-380,03$ & $9.709,02$ & $-139,52$ & $11.747,89$ & $-189,82$ & $4.053,54$ \\
\hline Ap. $s^{1}$ & $8.453,45$ & 71,81 & $14.760,28$ & 50,78 & $28.149,67$ & 6,12 & $29.985,98$ \\
\hline$A p+V s^{2}$ & $468.479,27$ & 30,13 & $586.802,33$ & 12,48 & $664.475,74$ & 0,90 & $670.494,26$ \\
\hline Ecótono & $162.621,75$ & $-101,88$ & $126.182,82$ & $-56,65$ & $83.227,51$ & $-3,32$ & $80.553,24$ \\
\hline Floresta & $135.951,80$ & $-104,52$ & $85.973,38$ & $-29,33$ & $69.414,12$ & $-4,42$ & $66.474,10$ \\
\hline $\mathrm{Im}^{3}$ & - & & 26,42 & $-65,29$ & 186,10 & $-1.064,13$ & 15,99 \\
\hline $\mathrm{Iu}^{4}$ & $1.424,81$ & 51,68 & $2.158,61$ & 26,80 & $2.403,40$ & 18,50 & $2.948,96$ \\
\hline Savana & $366.093,29$ & $-33,54$ & $319.414,55$ & $-16,51$ & $276.941,06$ & $-1,02$ & $274.140,66$ \\
\hline Silvicultura & 829,78 & 95,39 & $8.690,71$ & 51,68 & $17.401,28$ & 3,25 & $17.986,17$ \\
\hline
\end{tabular}

${ }^{1}$ Ap.s $=$ Pecuária com presença de savana; ${ }^{2} \mathrm{Ap}+\mathrm{Vs}=$ Pecuária com presença de vegetação secundária; ${ }^{3} \mathrm{Im}=$ Áreas degradadas por mineração; ${ }^{4} \mathrm{Iu}=$ Influência Urbana.

Fonte: os autores (2017).

As expressivas áreas de pastagem identificadas (Ap.s e Ap+Vs) estão diretamente ligadas ao crescimento do rebanho bovino no Estado, que se constituiu em 2016, segundo dados do Instituto Brasileiro de Geografia e Estatística, como o maior do país (IBGE, 2016), sendo feitas, para o desenvolvimento de tal atividade, inúmeras aberturas em áreas de vegetação nativa, principalmente de Savana (Cerrado) (CUNHA, 2006). Ramos et al. (2018, p. 819) explicam que a atividade pecuária é "responsável pelo uso e ocupação dos territórios antropizados e amplamente predominante no espaço rural mato-grossense, sendo um forte componente histórico na formação econômico-social". 
SILVA, G. J. O.; NEVES, S. M. A. S.; RAMOS, A. W. P.; MIRANDA, M. R. S.

Estado de conservação das áreas de preservação permanente de nascentes da bacia hidrográfica do rio Jauru/MTBrasil

Figura 2 - Cobertura vegetal e usos da terra da BHRJ, nos anos de 1986, 1996, 2006 e 2016

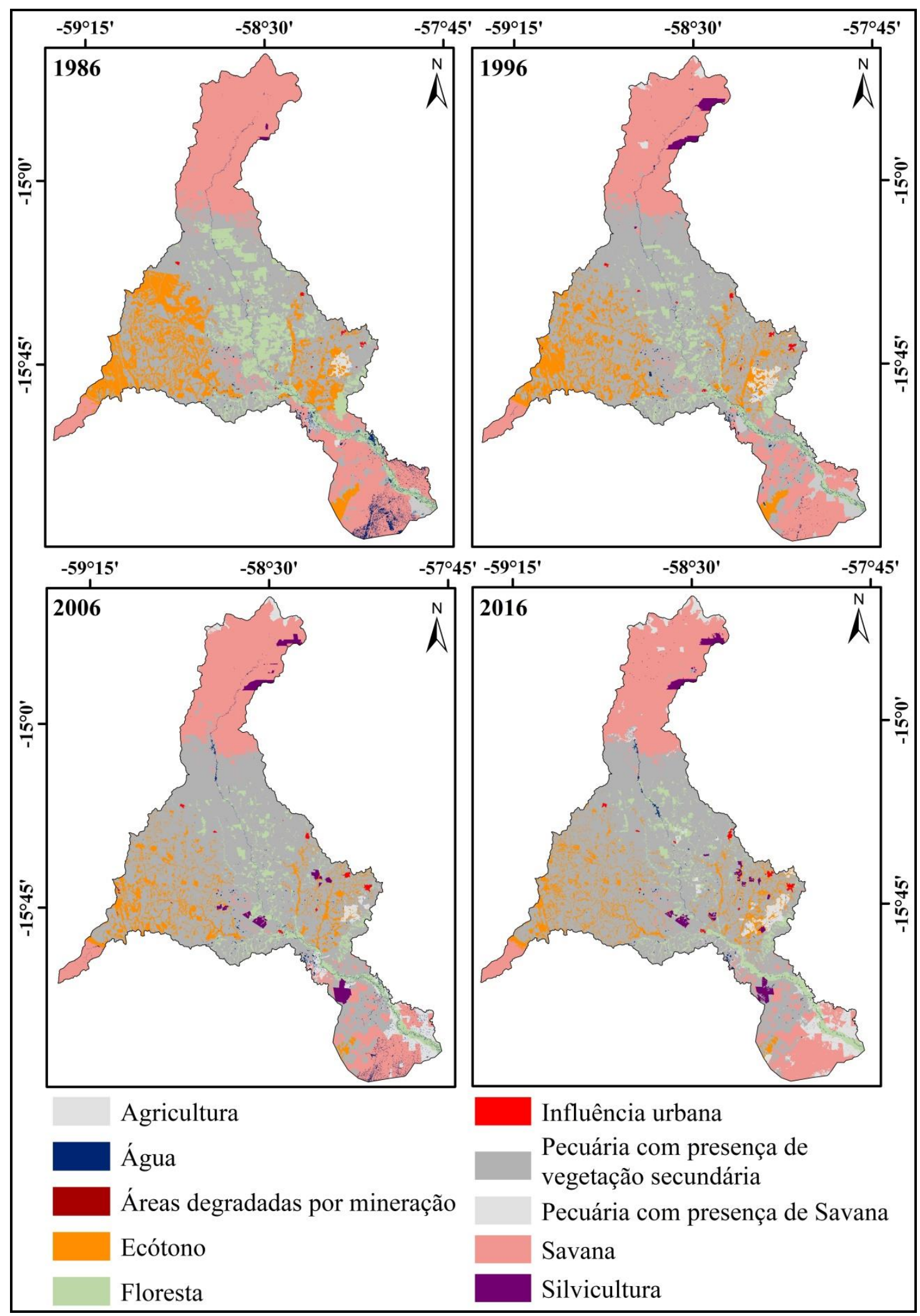

Elaboração: os autores (2017).

Revista Cerrados, Montes Claros/MG, v.18, n. 1, p. 03-22, jan./jun.-2020 
SILVA, G. J. O.; NEVES, S. M. A. S.; RAMOS, A. W. P.; MIRANDA, M. R. S.

Estado de conservação das áreas de preservação permanente de nascentes da bacia hidrográfica do rio Jauru/MTBrasil

Na classe Agricultura, foi também observado um aumento de área territorial, conflitante com as Áreas de Preservação Permanentes. No ano de 1986 o total de 10 APPs encontravam-se ocupadas indevidamente, de acordo com os parâmetros legais, número que cresceu acompanhado pela expansão agrícola para 16, 18 e chegou a 55, nos anos de 1996, 2006 e 2016, respectivamente. Conforme Souza (2015), o atual padrão do manejo agrícola por meio do despejo de poluentes orgânicos e inorgânicos e de insumos tem contribuído diretamente na contaminação dos recursos hídricos, gerando problemas de ordem ambiental e social.

As Áreas degradadas por mineração se portaram de maneira muito irregular, surgindo em 1996 e apresentando um crescimento de 69,88\% em 2006, porém, em 2016, ocorreu um decréscimo de 74,44\%. Não foram identificadas, durante o período analisado, tal atividade em áreas de nascentes. Esse fato pode estar relacionado com a implementação de leis voltadas à conservação ambiental, como o Cadastro Ambiental Rural (CAR) estabelecido em 2008, originário do Sistema Nacional de Informações do Meio Ambiente (SINIMA), que busca a recuperação de áreas degradadas (SANTOS, 2013).

A Influência urbana na bacia se mostrou pouco relevante, em 1986 totalizava 0,12\% passando para 0,25\% em 2016, ocupando 2 áreas de APPs. Os municípios contidos na bacia possuem extensão territorial significativa, entretanto as concentrações populacionais são reduzidas, sendo Cáceres a cidade mais populosa com 87.942 habitantes (IBGE, 2010).

A Silvicultura cresceu 38,20\% entre 1986 e 2016, no entanto não se relacionou com as nascentes. Esse tipo de atividade tem sido desenvolvido em áreas consideradas com alto grau de restrição, justamente por ter baixos níveis de impactos ambientais provocados (BACANI et al., 2015). A Pecuária com presença de Savana, que ocupava 0,72\% da bacia em 1986, obteve um crescimento de 0,54\% em 1996, porém, somente em 2006, a classe passou a ocupar áreas destinadas a APPs de nascentes e, em 2016, ocupando 2,56\% da bacia, foi identificada em áreas de 22 nascentes.

Dos usos antrópicos, a classe Pecuária com presença de vegetação secundária, em 1986, estendia-se por 40,06\% da bacia, existindo nesses locais 4.932 nascentes. Os números só cresceram, em 1996, sendo que 50,17\% da classe recobria mais de 6.150 nascentes, valor este que passou para 6.277, em 2006, e 6.595, em 2016, porém agora recobrindo 57,14\% da área. Resultado crível, uma vez que a economia dos municípios no qual a bacia está inserida 
SILVA, G. J. O.; NEVES, S. M. A. S.; RAMOS, A. W. P.; MIRANDA, M. R. S.

Estado de conservação das áreas de preservação permanente de nascentes da bacia hidrográfica do rio Jauru/MTBrasil

baseia-se na atividade pecuária. No entanto, esse tipo de uso é responsável por diversos impactos ambientais, como surgimento de voçorocas, desmatamento e compactação do solo por meio do pisoteio do gado (LORENZON et al., 2016), sendo que o último, próximo das nascentes, pode diminuir a capacidade de percolação. Além disso, deixando-as sujeitas à erosão laminar e ao assoreamento dos cursos d'água (CALHEIROS et al., 2004).

A classe Floresta recobria, em termos de extensão, 11,62\% da bacia (1986) e abrigava 832 nascentes, tais valores sofreram alterações significativas no decorrer das décadas correspondendo a 7,35\% e 219 nascentes, em 1996, 5,95\% (187 nascentes), em 2006, e 5,66\% e 107 nascentes, em 2016. Neto (2012) aponta, em seus estudos, que a classe Floresta é apresentada de forma suprimida estando associada à expansão da pecuária. As regiões de Ecótono também tiveram redução, só entre os anos de 1986 e 1996 perderam 8,05\% de área e 342 nascentes. Tais valores se agravaram e, em 2016, a classe passou a recobrir apenas 6,86\% da bacia e abrigar apenas 248 nascentes.

Dentre as formações vegetais, a Savana era a mais representativa em termos de extensão, pois, no ano de 1986, estendia-se por 31,30\% da bacia e 630 nascentes em sua área. Em 1996, teve cerca de 3,99\% suprimidos para fins antrópicos e, desse período até 2006, os valores continuaram decrescendo (3,57\%). Em 2016, passou a corresponder a 23,36\% e 208 nascentes, uma perca total de 91.952,62 hectares e 422 nascentes. A Savana é capaz de contribuir com os ambientes mais extremos e heterogêneos, tanto em termos espaciais quanto temporais, porém sua constante supressão tem ocasionado em modificações drásticas em sua fisionomia e perda da fauna (SAWYER; LOBO, 2008).

Conforme os dados acima e as análises feitas por Siebert et al. (2014), foi possível averiguar que, mesmo com os investimentos governamentais e o intuito de inibir a supressão vegetacional com fins de uso antrópico, verifica-se que na bacia do rio Jauru a ação humana tem sido constante e significativa acarretando a perda estimada de 110.534 ha de vegetação nativa, além de contribuir com o surgimento de impactos ambientais, como os processos erosivos.

Constatou-se o aumento gradativo dos valores do Índice de Transformação Antrópico na maioria das sub-bacias no decorrer do período de estudo (Tabela 3 e Figura 3), predominando o estado degradado da paisagem. Em 2016, as sub-unidades Córrego do Sangue e do Rio Aguapeí apresentaram estado regular de conservação, porém estas abrigavam 
SILVA, G. J. O.; NEVES, S. M. A. S.; RAMOS, A. W. P.; MIRANDA, M. R. S.

Estado de conservação das áreas de preservação permanente de nascentes da bacia hidrográfica do rio Jauru/MTBrasil

somente 1551 nascentes, que corresponde a $21,52 \%$, ou seja, 78,49\% das nascentes são encontradas nas sub-bacias, cujo estado é degradado.

Tabela 3 - Índice de Transformação Antrópica (ITA) das sub-bacias da BHRJ, nos anos de 1986,1996, 2006 e 2016

\begin{tabular}{|c|c|c|c|c|c|c|c|c|c|}
\hline \multirow{2}{*}{ SUB-BACIAS } & \multirow{2}{*}{$\begin{array}{c}\text { ÁREA } \\
\text { (HA) }\end{array}$} & \multicolumn{2}{|c|}{1986} & \multicolumn{2}{|c|}{1996} & \multicolumn{2}{|r|}{2006} & \multicolumn{2}{|c|}{2016} \\
\hline & & ITA & Estado & ITA & Estado & ITA & Estado & ITA & Estado \\
\hline $\begin{array}{l}\text { CÓRREGO ÁGUA } \\
\text { SUJA }\end{array}$ & $26.539,68$ & 4,87 & $\mathrm{R}$ & 5,30 & $\mathrm{D}$ & 5,55 & $\mathrm{D}$ & 5,56 & $\mathrm{D}$ \\
\hline $\begin{array}{l}\text { CÓRREGO DO } \\
\text { SANGUE }\end{array}$ & $31.623,74$ & 3,39 & $\mathrm{R}$ & 3,60 & $\mathrm{R}$ & 3,77 & $\mathrm{R}$ & 3,90 & $\mathrm{R}$ \\
\hline $\begin{array}{l}\text { CÓRREGO PADRE } \\
\text { RIBEIRÃO }\end{array}$ & $21.123,97$ & 3,02 & $\mathrm{R}$ & 4,86 & $\mathrm{R}$ & 4,92 & $\mathrm{R}$ & 5,15 & $\mathrm{D}$ \\
\hline $\begin{array}{l}\text { CÓRREGO } \\
\text { SANTÍSSIMO }\end{array}$ & $121.444,08$ & 3,05 & $\mathrm{R}$ & 4,82 & $\mathrm{R}$ & 5,28 & $\mathrm{D}$ & 5,31 & $\mathrm{D}$ \\
\hline $\begin{array}{l}\text { INTERBACIA DO } \\
\text { RIO JAURU }\end{array}$ & $126.741,26$ & 2,47 & PD & 2,91 & $\mathrm{R}$ & 3,10 & $\mathrm{R}$ & 5,14 & $\mathrm{D}$ \\
\hline RIBEIRÃO CAETÉ & $70.936,68$ & 4,53 & $\mathrm{R}$ & 5,44 & $\mathrm{D}$ & 5,66 & $\mathrm{D}$ & 5,98 & $\mathrm{D}$ \\
\hline RIBEIRÃO PITAS & $483.559,96$ & 3,04 & $\mathrm{R}$ & 4,01 & $\mathrm{R}$ & 4,93 & $\mathrm{R}$ & 5,18 & $\mathrm{D}$ \\
\hline RIO AGUAPEÍ & $188.323,15$ & 3,06 & $\mathrm{R}$ & 3,81 & $\mathrm{R}$ & 4,36 & $\mathrm{R}$ & 4,57 & $\mathrm{R}$ \\
\hline RIO BRIGADEIRO & $73.357,96$ & 3,57 & $\mathrm{R}$ & 5,31 & $\mathrm{D}$ & 5,46 & $\mathrm{D}$ & 5,59 & $\mathrm{D}$ \\
\hline
\end{tabular}

$\mathrm{D}=$ degradado; $\mathrm{PD}=$ pouco degradado; $\mathrm{R}=$ Regular. Organização: os autores (2017).

Em 1986, na sub-bacia Córrego Água Suja, que corresponde a 12,93\% da área da bacia hidrográfica do rio Jauru, o ITA ainda era enquadrado na classe regular. Em 1996, a porcentagem relacionada com o uso antrópico aumentou, e a classe Pecuária com presença de vegetação secundária correspondeu a $85,63 \%$, associado a esse valor o ITA passou para o estado degradado mantendo-se na mesma classe em 2016.

A sub-bacia do Córrego Sangue foi mantida dentro dos valores regulares de índice em todos os anos de pesquisa. As classes que mais se destacaram foram a Pecuária com presença de vegetação secundária e Savana, sendo que a última contribuiu diretamente para que o estado permanecesse regular, uma vez que a classe recobria 42,39\% da área, constatando que neste espaço ocorreram modificações nos componentes ambientais, porém em menor escala, o que é favorável às 640 nascentes do local. A sub-bacia Córrego Padre Ribeirão que detém 1,30\% das nascentes da BHRJ tinha, em 1986, 40,65\% de sua área recoberta por usos antrópicos. Tais valores cresceram 38,22\%, em 1996, chegando a 83,16\%, em 2016. Os valores de ITA aumentaram na mesma proporção que os usos antrópicos e a subbacia, considerada regular até 2006, passou para degrado em 2016. 
SILVA, G. J. O.; NEVES, S. M. A. S.; RAMOS, A. W. P.; MIRANDA, M. R. S.

Estado de conservação das áreas de preservação permanente de nascentes da bacia hidrográfica do rio Jauru/MTBrasil

Figura 3 - Índice de Transformação Antrópica (ITA) das sub-bacias BHRJ, nos anos de 1986,1996, 2006 e 2016

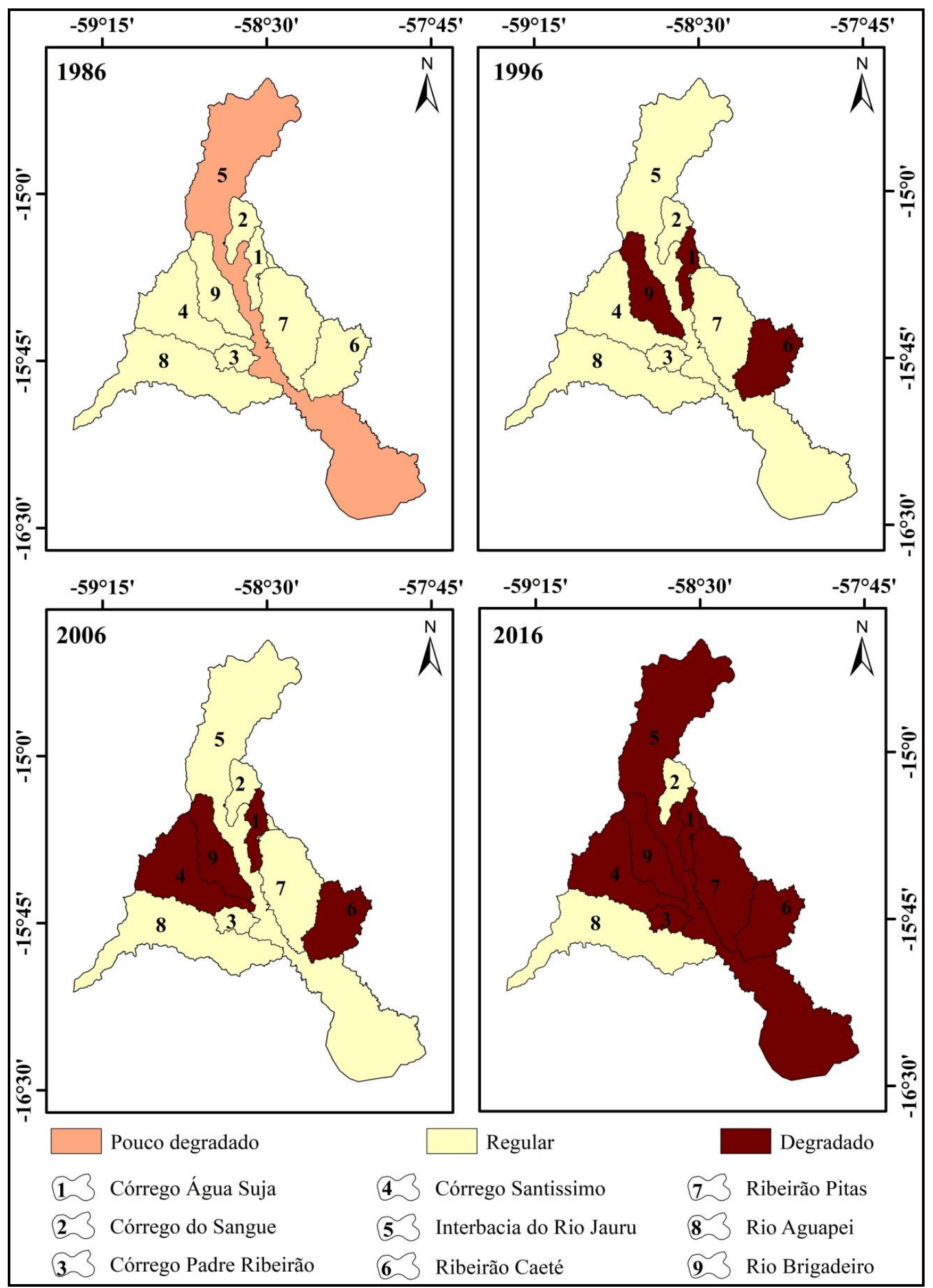

Elaboração: os autores (2017). 
SILVA, G. J. O.; NEVES, S. M. A. S.; RAMOS, A. W. P.; MIRANDA, M. R. S.

Estado de conservação das áreas de preservação permanente de nascentes da bacia hidrográfica do rio Jauru/MTBrasil

A bacia Córrego Santíssimo recebe influência de 1324 nascentes, sendo que, entre os anos de 1986 e 1996, a sub-unidade estava em estágio regular. A partir de 2006, o valor do índice de transformação acentuou-se, o que a tornou degrada. O mesmo aconteceu em 2016, evidenciando a gradativa e crescente substituição da cobertura vegetal por usos antrópicos que recobrem mais de $84,95 \%$ da sub-bacia.

A Interbacia do Rio Jauru foi a única que apresentou valor de ITA de correspondente a pouco degradado, o que é afável, visto que nesta área está o maior número de nascentes (1723), pois nos anos de 1996 e 2006 a sub-bacia ainda estava em estado regular, porém os usos antrópicos, como Pecuária com presença de vegetação secundária e Agricultura aumentaram e, em 2016, passou para estado de degradado.

A bacia Ribeirão Caeté, que abarca 225 nascentes, em 1986, apresentava valores de ITA próximos a cinco. Tais valores foram aumentando gradativamente e atualmente o estado da sub-bacia é considerado degradado, tendendo a ficar em estado de muito degrado em poucos anos, visto que os usos antrópicos representam 89,48\% da área.

A sub-bacia Ribeirão Pitas, que representa $10,27 \%$ do território da bacia do rio Jauru e 10,72\% das nascentes, possuía valores de ITA regulares até o ano de 2006. Em 2016, o índice de transformação passou para o estado de degradado. Com isso, as formações vegetais que poderiam contribuir com a inversão desse estado decresceram durante as décadas e, em 2016, representam apenas 17,89\%.

Oposto a isso temos a sub-bacia do Rio Aguapeí, que se manteve regular até 2016, fator esse que corrobora com a situação ambiental das 911 nascentes localizadas em suas extensões.

A sub-bacia do Rio Brigadeiro está entre as três que abarcam maior número de nascentes (1013), a unidade passou de estado regular, em 1986, para degrada, em 1996, e seguiu assim até o ano de 2016. Tal como nas demais sub-bacias com estado degradado, ela possui percentuais que chega a $89,00 \%$ de usos antrópicos tendo somente $10,98 \%$ de cobertura vegetal.

A bacia hidrográfica do rio Jauru possui cerca de 7,212 nascentes, cujas APPs de correspondem a 5.633,65 hectares que estão sendo submetidas aos mais variados usos, como demonstram as figuras 4 e 5 . 
SILVA, G. J. O.; NEVES, S. M. A. S.; RAMOS, A. W. P.; MIRANDA, M. R. S.

Estado de conservação das áreas de preservação permanente de nascentes da bacia hidrográfica do rio Jauru/MTBrasil

Figura 4 - Cobertura vegetal e usos da terra e distribuição das APPs de nascentes na BHRJ, nos anos de 1986 e 1996

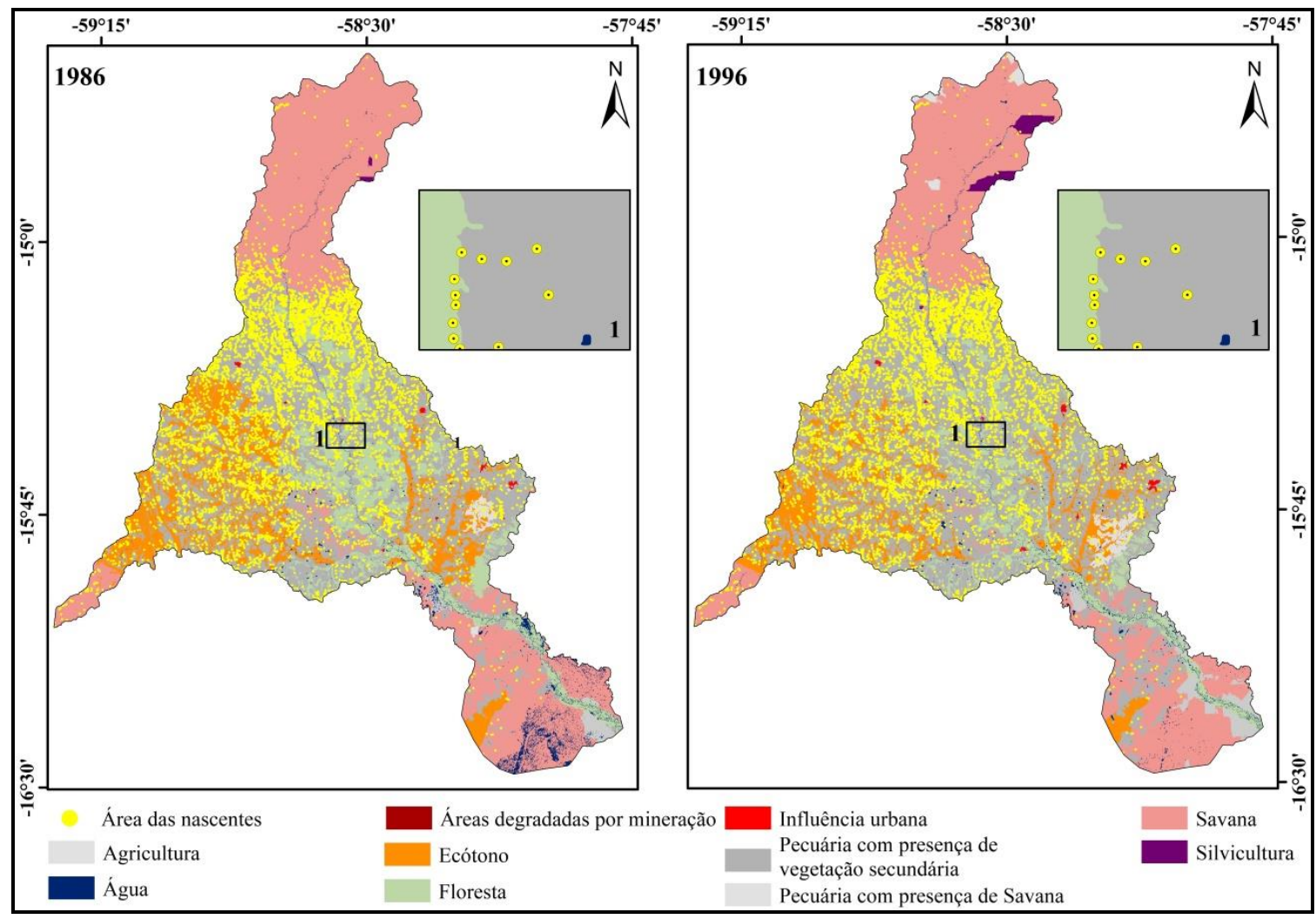

Elaboração: os autores (2017).

Em 1986, as classes Floresta, Savana e Ecótono correspondiam a 1775,19 hectares $(31,51 \%)$ das áreas de APPs de nascentes (Figura 4). As classes relacionadas com os usos antrópicos de maior representatividade (3852,73 hectares) eram Agricultura, Pecuária com presença de savana e Influência urbana totalizando 68,38\%. No ano de 1996, as classes relacionadas com a vegetação nativa decresceram 805,726 hectares $(14,30 \%)$, enquanto os usos antrópicos aumentaram em $85,52 \%$. Um aspecto preocupante, visto que as áreas desprovidas de APPs ficam sujeitadas ao escoamento superficial contribuindo com o assoreamento dos cursos d'água advindos do aparecimento de voçorocas (SANTOS et al., 2013).

As formações vegetais naturais, que já vinham sofrendo supressão, em 2006, foram reduzidas significativamente (Figura 5), a classe Floresta que, em 1986, correspondia a $11,52 \%$ do território passou a $1,50 \%$, o mesmo ocorreu com a Savana que passou de $8,83 \%$ para $2,88 \%$ e o Ecótono de 11,14\% para 3,44\%.

Revista Cerrados, Montes Claros/MG, v.18, n. 1, p. 03-22, jan./jun.-2020 
SILVA, G. J. O.; NEVES, S. M. A. S.; RAMOS, A. W. P.; MIRANDA, M. R. S.

Estado de conservação das áreas de preservação permanente de nascentes da bacia hidrográfica do rio Jauru/MTBrasil

Figura 5 - Cobertura vegetal e usos da terra e distribuição das APPs de nascentes na BHRJ, nos anos de 2006 e 2016

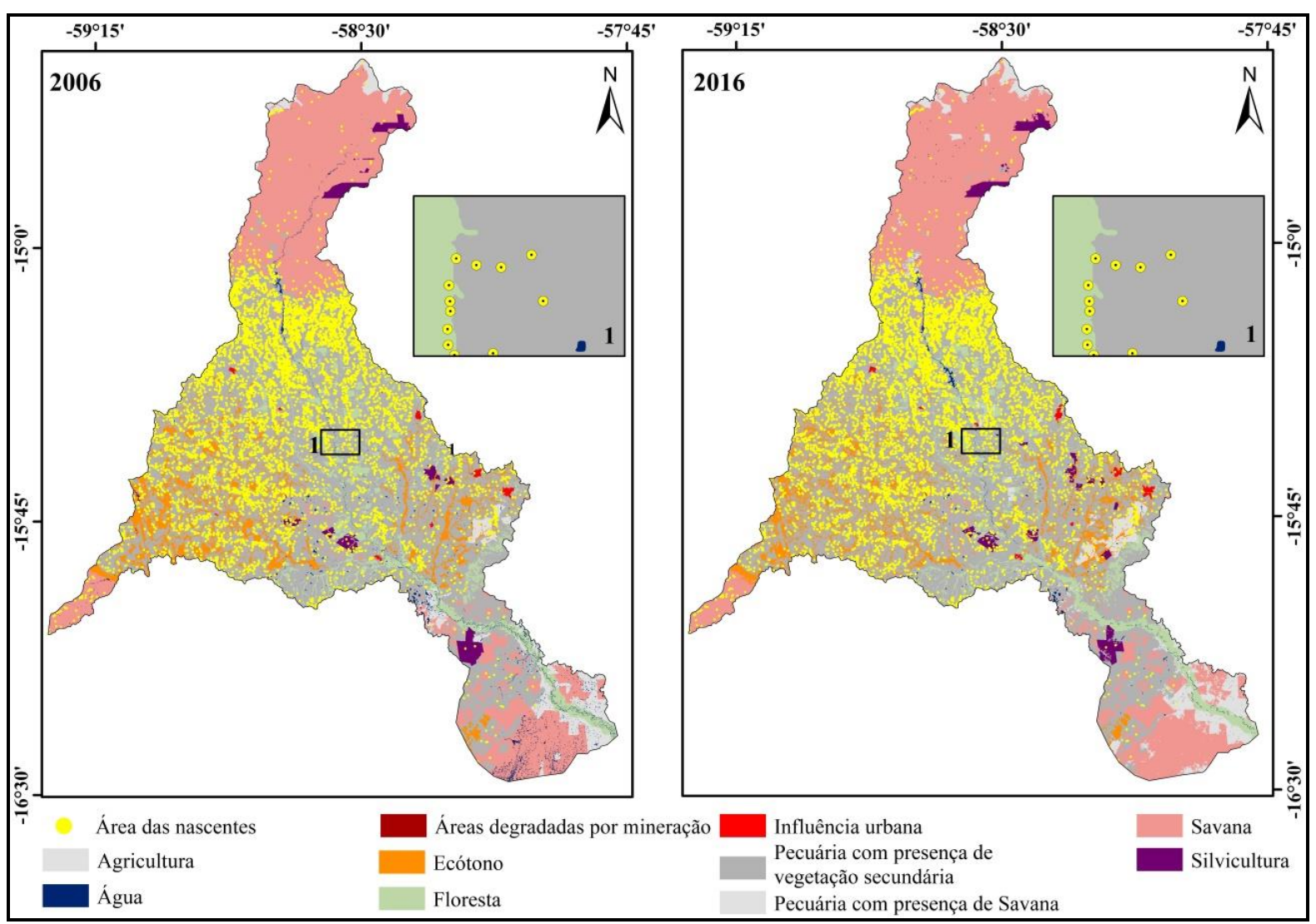

Elaboração: os autores (2017).

Análises semelhantes feitas por Rivero et al. (2009) demonstraram que, entre os anos de 2000 e 2006, ocorreram mudanças significativas em questões vegetacionais de muitos municípios mato-grossenses, havendo um crescimento de $80 \%$ da área não florestada/desmatada em 2006. Os autores salientam ainda que esse fato pode estar associado com a expansão gradativa das atividades agropecuárias, ocorrência confirmada com os dados da pesquisa, visto que os usos antrópicos nas APPs só aumentaram, por exemplo, a Pecuária com presença de vegetação secundária que era de 88,52\%, em 2006, e passou para 90,80\%, em 2016.

Verifica-se que algumas técnicas estabelecidas no ano de 2011 pelo CONAMA por meio da Resolução $n^{\circ}$ 429, que visa a implementação de espécies nativas e regeneração natural das APPs, não têm sido suficientes para a redução dos usos antrópicos em locais destinados às APPs de nascentes na BHRJ (BORGES et al., 2011). 
SILVA, G. J. O.; NEVES, S. M. A. S.; RAMOS, A. W. P.; MIRANDA, M. R. S.

Estado de conservação das áreas de preservação permanente de nascentes da bacia hidrográfica do rio Jauru/MTBrasil

\section{CONSIDERAÇÕES FINAIS}

A cobertura vegetal natural da bacia hidrográfica do rio Jauru, no período de três décadas, passou por constante processo de supressão. Diante disso, as áreas de APPs de nascentes da bacia sofreram fortes pressões em decorrência do desmate para o desenvolvimento da atividade pecuária, principal atividade econômica dos municípios que compõem a bacia.

O Índice de Transformação Antrópica evidenciou que predomina nas sub-bacias da BHRJ o estado de conservação ambiental degradado, com exceção das bacias hidrográficas do rio Aguapeí e córrego do Sangue que se encontram em estado regular, o que demonstra os impactos causados pelas ações antrópicas no ambiente.

Diante disso, ficou evidente a necessidade do planejamento do uso da terra na bacia do rio Jauru, com destaque às suas APPs, visto que é a contribuinte hídrica do bioma Pantanal, apresentando grande relevância ambiental.

\section{REFERÊNCIAS}

ALVES, G. M. R.; FERREIRA, M. F. M. Uso do solo em Áreas de Preservação Permanente (APP) na bacia do córrego do Pântano, município de Alfenas-MG. Revista de Geografia PPGEO - UFJF, Juiz de Fora/MG, v. 6, n. 4, p. 329-337, 2016.

BACANI, V. M; SAKAMOTO, A. Y.; LUCHIARI, A.; QUÉNOL, H. Sensoriamento remoto e SIG aplicados à avaliação da fragilidade ambiental de bacia hidrográfica. MERCATOR, Fortaleza, v. 14, n. 2, p. 119-135, 2015.

BARROS, C. A. O uso agropecuário e sua implicação na paisagem da bacia hidrográfica do Rio Jauru, Mato Grosso - Brasil. 2018. 42 f. Dissertação (Mestrado Interdisciplinar em Ambiente e Sistemas de Produção Agrícola) - Universidade do Estado de Mato Grosso, Tangará da Serra/MT, 2018.

BORGES, L. A. C.; REZENDE, J. L. P.; PEREIRA, J. A. A.; JUNIOR, L. M. C.; BARROS, D. A. Áreas de preservação permanente na legislação ambiental brasileira. Ciência Rural, Santa Maria/RS, v. 41, n. 7, p. 1202-1210, 2011.

BRASIL. Lei Federal n. ${ }^{\circ}$ 12.651, de 25 de maio de 2012. Dispõem sobre a proteção da vegetação nativa e de outras providências. Diário Oficial da República Federativa do Brasil, Brasília, DF. Disponível em: <http://www.planalto.gov.br/ccivil_03/_Ato2011 2014/2012/Lei/L12651.htm>. Acesso em: 26 de setembro de 2017. 
SILVA, G. J. O.; NEVES, S. M. A. S.; RAMOS, A. W. P.; MIRANDA, M. R. S.

Estado de conservação das áreas de preservação permanente de nascentes da bacia hidrográfica do rio Jauru/MTBrasil

BRASIL. Ministério do Meio Ambiente - MMA. Projeto Probio. Avaliação e ações para a conservação da biodiversidade nos biomas Cerrado e Pantanal, 1999. Disponível em: <https://www.mma.gov.br/biodiversidade/projetos-sobre-a-biodiveridade/item/486probio.html>. Acesso em: 20 de setembro de 2017.

CÂMARA, G.; SOUZA, R. C. M.; FREITAS, U. M.; GARRIDO, J. Spring: Integrating remote sensing and gis by object-oriented data modelling. Computers \& Graphics, England/UK, v. 20, n. 3, p. 395-403, 1996.

CALHEIROS, R. O.; TABAI, F. C. V.; BOSQUILIA, S. V.; CALAMARI, M. Preservação e recuperação das nascentes de água e vida. Piracicaba/SP: Comitê das Bacias Hidrográficas dos Rios Piracicaba, Capivari e Jundiaí - CTRN, 2004. 40 p.

CRUZ, C. B. M.; TEIXEIRA, A. J. A.; BARROS, R. S.; ARGENTO, M. S. F.; MAYR, L. M.; MENEZES, P. M. L. Carga Antrópica da Bacia Hidrográfica da Baía de Guanabara. In: SIMPÓSIO BRASILEIRO DE SENSORIAMENTO REMOTO, 9., 1998, Santos/SP. Anais eletrônicos [...] São José dos Campos/SP: INPE, 1998. p. 99-109. Disponível em: <http://marte.sid.inpe.br/col/sid.inpe.br/deise/1999/02.09.11.15/doc/4_48p.pdf>.

CUNHA, J. M. P. Dinâmica migratória e o processo de ocupação do Centro-Oeste brasileiro: o caso de Mato Grosso. Revista Brasileira de Estudos de População, Rio de Janeiro, v. 23, n. 1, p. 87-107, 2006.

DESTRO, G. F. G.; CAMPOS, S. Análise de conflitos do uso da terra. Revista Brasileira de Geomática, Presidente Prudente/SP, v.1, n. Especial, p. 983-988, 2007.

ESRI. ArcGis 10.5. Environmental Systems Research Institute, Inc. Redlands/CA. 2017.

GOUVEIA, R. G. L.; GALVANIN, E. A. S.; NEVES, S. M. A. S. Aplicação do índice de transformação antrópica na análise multitemporal da bacia do córrego do Bezerro Vermelho em Tangará da Serra-MT. Revista Árvore, Viçosa/MG, v. 37, n. 6, p. 1045-1054, 2013.

IBGE. Instituto Brasileiro de Geografia e Estatística. Censo demográfico 2010.

Características da população e dos domicílios: resultados do universo. Rio de Janeiro: IBGE, 2011. Disponível em:

<https://biblioteca.ibge.gov.br/visualizacao/periodicos/93/cd_2010_caracteristicas_populacao _domicilios.pdf >. Acesso em: 18 de novembro de 2017.

IBGE. Instituto Brasileiro de Geografia e Estatística. Manual técnico da vegetação brasileira. 3. Ed. Rio de Janeiro: IBGE, 2013. 171 p.

IBGE. Instituto Brasileiro de Geografia e Estatística. Pesquisa Pecuária Municipal, 2016. Disponível em: <https://agenciadenoticias.ibge.gov.br/agencia-noticias/2012-agenciadenoticias/noticias/16994-rebanho-de-bovinos-tem-maior-expansao-da-serie-historica.html>. Acesso em: 27 junho de 2017. 
SILVA, G. J. O.; NEVES, S. M. A. S.; RAMOS, A. W. P.; MIRANDA, M. R. S.

Estado de conservação das áreas de preservação permanente de nascentes da bacia hidrográfica do rio Jauru/MTBrasil

LORENZON, T. H.; PAIVA, S. L. P.; NEVES, R. J.; NEVES, S. M. A. S.; NUNES, E. S. Analysis of the conservation state from the permanente protection areas at the springheads and of the water from Cabaçal river drainage basin, Mato Grosso State, Brazil.

GEOGRAFIA, Rio Claro/SP, v. 40. n. Especial, p. 145-161, 2015.

\section{LUZ, C. C. S. Vulnerabilidade ambiental e exploração agrícola da bacia hidrográfica do}

Rio Jauru - Mato Grosso. 2018. 79 f. Dissertação (Mestrado Interdisciplinar em Ambiente e Sistemas de Produção Agrícola) - Universidade do Estado de Mato Grosso, Tangará da Serra/MT, 2018.

MACEDO, M. J. H.; SANTOS, F. A. C.; SOUSA, F. D. A. S. Geoprocessamento aplicado as características físicas e biofísicas da Bacia Hidrográfica do Rio Parnaíba. Revista de Geografia (Recife), Recife, v. 34, n. 2, p. 170-193, 2017.

MIRANDA, M. R. S.; NEVES, S. M. A. S.; RAMOS, A. W. P. Caracterização das unidades de paisagem da bacia hidrográfica do rio Jauru -Mato Grosso, Brasil. Caderno de Geografia, Belo Horizonte, v. 29, n. 58, p. 765-785, 2019.

NARDINI, R. C.; GOMES, L. N.; RIBEIRO, F. L.; LOPES, P. A.; VENDRAME, P. R. S. Avaliação das áreas de conflito de uso em áreas de preservação permanente do Córrego Pedroso - PR. Ciência Geográfica, Bauru/SP, v. 23, n. 2, p. 644-653, 2019.

NETO, J. C. A. S. Indicação para o uso da terra na bacia hidrográfica do rio Salobra-Serra da Bodoquena, Mato Grosso do Sul. RA'E GA, Curitiba, v. 25, n. 2, p. 279-304, 2012.

OLIVEIRA, O. A.; TEIXEIRA, T. M. A.; PASSO, D. P. Mapeamento dos conflitos de uso da terra em áreas de preservação permanente dos rios que contribuem para o barramento do rio Paranã, Formosa-GO. Boletim Goiano de Geografia, Goiânia, v. 38, n. 3, p. 491-515, 2018.

RAMOS, A. W. P.; LUZ, C. C. S.; NEVES, S. M. A. S.; FREITAS, L. E.; NEVES, L. F. S. Análise da capacidade e conflito de uso da terra na bacia hidrográfica do Córrego da Piraputanga-MT, Brasil. Caderno de Geografia, Belo Horizonte, v. 28, n. 55, p. 812-827, 2018.

RIVERO, S.; ALMEIDA, O.; ÁVILA, S.; OLIVEIRA, W. Pecuária e desmatamento: uma análise das principais causas diretas do desmatamento na Amazônia. Nova Economia, Belo Horizonte, v. 19, n. 1, p. 41-66, 2009.

ROSS, J. L. S. Ecogeografia do Brasil: subsídios para o planejamento ambiental. São Paulo: Oficina de Textos, 2006. 208 p.

RODRIGUES, L. C.; NEVES, S. M. A. S.; NEVES, R. J.; GALVANIN, E. A. S.; KREITLOW, J. P. Dinâmica da antropização da paisagem das sub-bacias do rio Queima Pé, Mato Grosso, Brasil. ESPACIOS, Caracas/VEN, v. 36, n. 10, p. 5-13, 2015.

SAWYER, D.; LOBO, A. S. O papel da sociedade no estabelecimento de políticas públicas para as savanas. In: FALEIRO, F. G.; FARIAS NETO, A. L. (org.). Savanas: desafios e 
SILVA, G. J. O.; NEVES, S. M. A. S.; RAMOS, A. W. P.; MIRANDA, M. R. S.

Estado de conservação das áreas de preservação permanente de nascentes da bacia hidrográfica do rio Jauru/MTBrasil

estratégias para o equilíbrio entre sociedade, agronegócio e recursos naturais. Planaltina/DF: EMBRAPA Cerrados, 2008. p. 1153-1180.

SANTOS, E. L. F.; MEDEIROS, S. H. Q.; SILVA, C. J. Educação ambiental e diálogo de saberes em região de nascentes do Pantanal: Reserva do Cabaçal, Mato Grosso, Brasil.

Ciência \& Educação, Bauru/SP, v. 19, n. 4, p. 879-896, 2013.

SANTOS, N. G. B. Gestão do Projeto de Recuperação de Áreas Degradadas: Estratégia para aperfeiçoamento. 2013. 149 f. Dissertação (Mestrado em Engenharia Agrícola) Universidade Federal de Mato Grosso, Rondonópolis/MT, 2013.

SIEBERT, D. E.; VECCHIATO, A. B.; SALOMÃO, F. X. T. Descrição do Uso e Ocupação da Cabeceira do Rio Jauru (MT) e Caracterização dos Processos de Degradação Ambiental.

E\&S - Engineering and Science, Cuiabá, v. 1, n. Especial, p. 1-8, 2014.

SOUZA, A. V. V. Influência dos usos e ocupação do solo na qualidade da água do Rio Vermelho no sudeste de Mato Grosso. 2015. 80 f. Dissertação (Mestrado em Geografia) Universidade Federal de Mato Grosso, Rondonópolis/MT, 2015.

TARIFA, J. R. Mato Grosso: Clima - Análise e representação cartográfica. Cuiabá: Entrelinhas, 2011. 102 p.

VALENTE, O. F.; GOMES, M. A. Conservação de Nascentes: hidrologia e manejo de bacias hidrográficas de cabeceiras. Viçosa/MG: Aprenda Fácil, 2005. 210 p.

\section{Autores}

Gessica de Jesus Oliveira Silva - Possui Graduação e Mestrado em Geografia, ambos cursados na Universidade do Estado de Mato Grosso (UNEMAT).

Sandra Mara Alves da Silva Neves - Possui graduação em Geografia pela Universidade Federal de Mato Grosso do Sul (UFMS), Mestrado em Geografia pela Universidade Estadual Paulista Júlio de Mesquita Filho (UNESP) e Doutorado em Ciências (Geografia) pela Universidade Federal do Rio de Janeiro (UFRJ) e estágios de pós-doutorado em Geografia na Universidade Federal do Rio de Janeiro (UFRJ) e em Ecologia de Paisagem na Universidad Complutense de Madrid (UCM). Atualmente é professora adjunta do curso de Geografia da Universidade do Estado de Mato Grosso (UNEMAT) e docente permanente nos Programas de pós-graduação em Ambiente e Sistemas de Produção Agrícola e Geografia da mesma instituição.

Alexander Webber Perlandim Ramos - Possui graduação em Geografia e Mestrado em Ambiente e Sistemas de Produção Agrícola, ambos cursados na Universidade do Estado de Mato Grosso (UNEMAT). Atualmente é doutorando pelo Programa de Pós-Graduação em Geografia da Universidade Federal de Minas Gerais (UFMG). 
SILVA, G. J. O.; NEVES, S. M. A. S.; RAMOS, A. W. P.; MIRANDA, M. R. S.

Estado de conservação das áreas de preservação permanente de nascentes da bacia hidrográfica do rio Jauru/MT-

Brasil

Miriam Raquel da Silva Miranda - Possui Graduação em Geografia e Mestrado em Ambiente e Sistemas de Produção Agrícola, ambos cursados na Universidade do Estado de Mato Grosso (UNEMAT). Atualmente é professora assistente do curso Geografia da Universidade do Estado de Mato Grosso (UNEMAT).

Artigo recebido em: 10 de janeiro de 2020.

Artigo aceito em: 22 de fevereiro de 2020.

Artigo publicado em: 03 de março de 2020. 